\title{
PROJETOS DE TRABALHO: FERRAMENTA PARA FORMAÇÃO CONTINUADA DE PROFESSORES NA ESCOLA
}

\author{
Marcos BALTAR \\ Maria Eugênia T. GASTALDELLO \\ Marina A. CAMELO \\ Priscila K. DERLAM \\ Universidade de Caxias Sul
}

Resumo O presente artigo discute a pedagogia de projetos de trabalho como contribuição para o desenvolvimento de competências envolvendo professores em processo de formação continuada. O escopo teórico está alicerçado nas contribuições do Interacionismo sociodiscursivo de Bronckart (1999), principalmente, no que tange aos conceitos de atividade e ação de linguagem, nos aportes de Hernández (1998a, 1998b) sobre projetos de trabalho, de Perrenoud (1999) acerca do conceito de competência e de Baltar (2006) acerca do conceito de competência discursiva. Os procedimentos metodológicos seguem a dinâmica da pesquisa-ação: problematização, ação, reflexão, transformação, conforme Andaloussi (2004), a partir do acompanhamento da criação e execução de um projeto de trabalho em uma escola pública de Flores da Cunha-RS. Os resultados indicam o desenvolvimento de múltiplas competências dos sujeitos partícipes do projeto e a necessidade da escola repensar seu planejamento didático-pedagógico, na direção de um trabalho colaborativo, que promova na comunidade escolar, interdisciplinarmente, sua emancipação sociodiscursiva.

Palavras-chave: projetos de trabalho, pesquisa-ação, atividades de linguagem, competência discursiva, formação continuada

Abstract The present article argues the pedagogy of work projects as contribution for the development of competences involving teachers in a continuing education situation. The theories involved are the socialdiscursive Interactionism of Bronckart (1999), mainly, the concepts of activity and action of language, the work projects of Hernández (1998a, 1998b), the Perrenoud's competence concept (1999) and Baltar's discursive competence concept (2006). The methodological procedures 
follow the dynamics of the research-action: action, reflection, action, as Andaloussi (2004), analyzed from the accompaniment of the creation and execution of a project of work in a public school of Flores da Cunha. The results showed the development of multiple competences of the citizens of the project and the necessity of the school to rethink its didactic-pedagogical planning, towards to a collaborative work, that promotes in the school community, its socialdiscursive emancipation.

Keywords work projects, research-action, activity of language, discursive competence, continued formation

Resumen Este artículo discute la contribución de la pedagogía de proyectos para el desarrollo de las capacidades de los profesores que están insertados en la formación continuada. El trabajo se construye sobre el cuadro teórico del Interacionismo de Bronckart (1999), en especial a lo que se refiere a los conceptos de la actividad y la acción de la lenguaje, del concepto de los proyectos de trabajo de Hernández (1998a, 1998b) y aquél de la capacidad de Perrenoud (1999), además de la noción de capacidad discursiva de Baltar (2006). Los procedimientos metodológicos siguen la dinámica de la investigaciónacción: acción, reflexión, acción, como Andaloussi (2004), y se estructuran sobre la observación y el acompañamiento de la creación y ejecución de un proyecto de trabajo en una escuela pública de Flores da Cunha. Los resultados indican el desarrollo de capacidades múltiples de los ciudadanos involucrados en el proyecto y la necesidad de la escuela repensar su planeamiento didáctico-pedagógico, siguiendo en la dirección de un trabajo colaborativo que promueva en la comunidad de la escuela su emancipación sociodiscursiva.

Palabras clave proyectos de trabajo, investigación-acción, actividad de la lengua, capacidad discursiva, formación continuada

\section{Introdução}

Esse artigo discute a formação continuada de professores de uma escola pública municipal de Flores da Cunha, visando à construção de práticas de ensinagem, que possibilitem o desenvolvimento de múltiplas competências, notadamente a competência discursiva, nos estudantes de ensino fundamental, por 
intermédio da pedagogia de projetos de trabalho, tendo em vista agregar qualidade ao processo de emancipação social dessa população escolar.

Em abril de 2006, o grupo de pesquisa UCS/CNPq EGET: estudos de gêneros textuais foi procurado pela SMECD de Flores da Cunha para colaborar no processo de formação continuada dos professores de Língua Portuguesa, ensino fundamental, da rede municipal, principalmente no sentido de sensibilizá-los para o trabalho de leitura e de produção de textos na escola, na ótica da pedagogia de projetos e da ensinagem ${ }^{1}$ por gêneros textuais.

A partir disso, elaborou-se uma oficina de 20 horas da qual participaram dez professores, representando cinco escolas. Como trabalho de culminância dessa oficina os professores foram convidados a construir um projeto de leitura para ser desenvolvido na sua escola e, posteriormente, acompanhado pela equipe de pesquisa..

O que vamos analisar agora é a co-construção e a execução do projeto de trabalho denominado HIP HOP: promovendo a leitura através da arte e da cultura, de autoria da de uma professora participante da oficina, que visava a aprimorar o nível de competência de leitura dos sujeitos envolvidos, despertando seu interesse por diferentes gêneros textuais a partir do movimento Hip-Hop. O projeto teve início dia 29 de setembro de 2006 e a culminância no dia 16 de dezembro de 2006, data da Multifeira anual da escola.

Ao longo desse período, oito atividades foram planejadas e executadas pelos professores e estudantes da escola, buscando uma perspectiva interdisciplinar. A equipe de pesquisa assessorou a coordenação do projeto, estando presente em três reuniões que antecederam o início do empreendimento, discutindo a elaboração do gênero textual projeto. A partir dessas discussões, a professora de Língua Portuguesa e a coordenadora pedagógica, mediante o processo de escrita e reescrita, finalizaram o projeto e, dentro do cronograma quinzenal de reuniões pedagógicas da escola, socializaram as diretrizes de sua execução para os outros professores que futuramente se envolveriam nas atividades.

A seguir, apresentamos algumas considerações teóricas acerca da dinâmica de projetos de trabalho e da abordagem por competências

\footnotetext{
${ }^{1}$ Utilizamos esse termo com o intuito de ressaltar a imbricação entre ensino e aprendizagem, refutando qualquer leitura dicotômica desses processos.
} 
e do interacionismo sociodiscursivo, que deram suporte às análises das atividades realizadas no projeto. Alguns comentários que faremos estão subsidiados pela avaliação feita juntamente com os professores coordenadores do projeto, em reunião realizada na Escola Municipal Leonel Brizola, em fevereiro de 2007.

\section{Projetos de trabalho como ferramenta educativa}

Hernandez (1998a, 1998b) já insistia na tese de que a melhor maneira de organizar um currículo na escola é por intermédio de projetos de trabalho. Alguns diretores, coordenadores pedagógicos e professores, quando argüidos por pesquisadores que atuam na formação continuada, têm relatado que trabalham ou querem trabalhar por projetos na suas escolas, entretanto muitos que dizem trabalhar por projetos referem-se a uma mera rotina de eventos que fazem parte do calendário escolar como: páscoa, dia do índio, dia das mães, festa junina, dia dos pais, semana da pátria, dia da árvore, dia da criança etc, organizados em atividades desarticuladas sem a finalidade de ensinagem.

Esse autor defende o potencial educativo dos projetos de trabalho pelo fato de esse dispositivo priorizar estratégias de ensino geradoras de aprendizagens significativas. Para ele, os projetos têm, entre outros propósitos, o de horizontalizar as ações de poder, tentando dar vez e voz aos participantes, além de possibilitar crescentes modificações na postura do professor, que passa a exercer o papel de orientador, estimulador, auxiliando, em princípio, somente quando solicitado; e do aluno, que abandona o papel de receptor passivo, tornando-se sujeito ativo do processo de ensinagem, articulando informações a fim de que elas se transformem em conhecimentos mediadores de competências.

Perrenoud $(1999,2002)$ sugere que para o aluno desenvolver suas competências, deve trabalhar mais, com disposição de correr novos riscos, projetar-se e questionar-se, de preferência através de situaçõesproblema ou de seu engajamento na execução de atividades que façam parte de um projeto de trabalho.

De fato, os projetos de trabalho podem provocar potentes mudanças na dinâmica escolar, por formar indivíduos com uma visão mais global da realidade, vinculando a ensinagem a situações e problemas 
significativos, reais ou mais próximos possível da realidade, trabalhando a partir da pluralidade e da diversidade de perspectivas, podendo preparar os estudantes para desenvolver múltiplas competências que poderão acompanhá-los durante a vida.

Uma vez cientes das potencialidades da pedagogia dos projetos de trabalho, os professores assumem uma postura inovadora superando as limitações do espaço escolar: físico e discursivo, viabilizando ao estudante a função de protagonista de sua própria formação.

Uma característica marcante dos projetos de trabalho é a tendência à interdisciplinaridade, pois, mesmo que os projetos estejam vinculados a uma única disciplina, os sujeitos que deles participam acabam se envolvendo em atividades múltiplas, buscando saberes que vão além da linearidade disciplinar. A organização de um projeto de trabalho pode se dar a partir de um tema gerador/núcleo temático, que pode ser proposto por professores ou pelos estudantes. Quando o tema for escolhido pelo professor, deve provocar a motivação e o envolvimento dos estudantes para que consigam realizar todas as fases do projeto. O tema precisa estar vinculado a um problema a ser resolvido, constituindo assim uma autêntica atividade pedagógica, caso contrário caracteriza-se como um mero ativismo que apenas mantém o aluno ocupado. A duração de um projeto de trabalho é variável, depende de seu objetivo e de sua complexidade, podendo durar dias, horas ou meses. A dinâmica de um projeto pode caracterizar-se tanto pela predominância da horizontalidade quanto da verticalidade que se possa dar ao problema em questão. Quanto maior for a articulação entre horizontalidade e verticalidade de abordagem, maior será a potencialidade de ações inter e transdiciplinares. $\mathrm{Na}$ ausência de articulação entre as contribuições oriundas dos diferentes campos de saber, é inevitável o recuo epistêmico-metodológico em direção a práticas pluri ou multidisciplinares.

Segundo Hernández (1998a), para realizar um projeto é importante compreender que não há um método a seguir, mas sim uma série de condições a respeitar. As fases de um projeto não são imutáveis, devem depender do desenrolar das atividades. Os ajustes feitos no decorrer da execução do projeto, quando necessários, indicando flexibilidade atitudinal, viabilizam a autenticidade da proposta, mantendo o grau motivacional dos sujeitos envolvidos 
Os projetos de trabalho também podem ser organizados tendo como ponto de partida a resolução de problemas. A partir de questões instauradas, decorrentes de uma situação-problema proposta, parte-se para a construção de estratégias resolutivas. Esse empreendimento pode ser organizado em várias etapas, exigindo um efetivo envolvimento de todos os participantes do princípio ao fim. Dependendo da característica do projeto, os estudantes passam a construir alternativas de estratégias de busca, de tratamento da informação, de organização, de discussão das informações na direção da construção de saberes individuais e coletivos, fruto da interação desencadeada entre os participantes do projeto, enfatizando a diversidade de implicações possíveis, decorrentes de cada proposta resolutiva elencada.

Um projeto de trabalho, seja ele centrado num tema gerador ou numa situação-problema, culmina com a avaliação de todo o processo. Essa avaliação passa então a ser planejada, compartilhada e monitorada continuamente, durante todas as etapas do projeto pelos sujeitos envolvidos, para que a compreensão do processo possa gerar mecanismos que potencializem as energias mobilizadas. Na etapa conclusiva, realiza-se a avaliação global, tempo em que os professores, juntamente com os estudantes, constroem uma retrospectiva do projeto para avaliar se o projeto mobilizou as habilidades e competências almejadas, se a situação-problema foi resolvida, se as estratégias utilizadas foram eficazes, se alguma atividade poderia ser reorganizada, se o projeto contribuiu para avanços de aprendizagens e em que medida esses avanços contribuíram para qualificar o desenvolvimento dos sujeitos envolvidos etc.

Num projeto de trabalho é importante conceber o estudante livre para buscar e processar informações, de tal modo que essas informações possam se transformar em conhecimentos propícios à construção de saberes ${ }^{2}$ processuais e procedurais conscientes para atuar com destreza no mundo da vida. Essa liberdade operatória, contemplando os estilos e os ritmos de aprendizagem, favorece o desenvolvimento de habilidades e competências singulares, tanto de natureza cognitiva quanto sociointerativa.

\footnotetext{
${ }^{2} \mathrm{~A}$ noção de saber à qual fazemos alusão não se restringindo ao savoire-faire, contempla também a idéia de savoire-vivre.
} 
Os projetos de trabalho, compreendidos como contratos de cooperação, permitem extrapolar a convencional relação professorestudante, criando espaço para a auto-regulagem da conduta de ambos. Além disso, outros segmentos da comunidade escolar: funcionários e pais, podem colaborar para o enriquecimento do processo dialógico entre os diversos extratos da sociedade, viabilizando cenários frutíferos à interação sociodiscursiva.

\section{Atividades do projeto e competências}

Perrenoud $(1999,2002)$ adverte que as escolas, muitas vezes, dizem trabalhar com a abordagem por competências, mas na verdade, continuam priorizando a transmissão de informações e, em alguns casos, enfatizando a construção de conhecimentos como tarefa de culminância do trabalho educativo, deixando à deriva a tarefa do desenvolvimento de competências durante o processo de execução de seus projetos educacionais. De fato essa mudança em direção à abordagem de ensinagem por competências não é tarefa fácil, pois implica importantes transformações nos projetos pedagógicos das unidades de ensino, no planejamento anual escolar, no planejamento e na condução das atividades de ensinagem dos professores, na evolução desse planejamento disciplinar em direção a um planejamento interdisciplinar e, sobretudo, na (re)definição de papéis e responsabilidades entre gestores, professores e estudantes no ambiente discursivo escolar.

Isso supõe a superação do ensino isolado e fragmentado por disciplinas, em direção da inter/transdisciplinariedade. Para tanto, é fundamental a construção de novos cenários, ambientes e situações de ensinagem, que sejam propícios para o vicejamento de projetos de trabalho articulados pela comunidade escolar, endereçados ao desenvolvimento de múltiplas competências, entre as quais encontrase a competência discursiva.

Baltar (2006) considera que um dos objetivos importantes, senão o principal, do trabalho do professor de Língua Portuguesa, é desenvolver em si próprio e nos estudantes a competência discursiva, por intermédio de atividades/ações de linguagem significativas, buscando emancipação para interagir sociodiscursivamente, nos 
diversos ambientes da sociedade. $\mathrm{O}$ autor considera competência discursiva como:

[...] um amálgama de capacidades que o usuário de uma língua natural atualiza e concomitantemente desenvolve, quando participa das atividades situadas de linguagem que ocorrem nos diversos ambientes discursivos da sociedade. Além de capacidades lingüisticas, textuais e comunicativas, para viver de forma autônoma, esse usuário necessita compreender as diferentes formacõos discursivas e os respectivos discursos que compõem os ambientes discursivos dessa sociedade. Dominar a maior gama possivel de gêneros textuais, orais e escritos, disponiveis no inventário construído sócio-historicamente corrobora para o usuário desenvolver sua competência discursiva, já que é por intermédio dos gêneros textuais que se dá toda a interação sociodiscursiva. A competência discursiva do usuário de uma lingua abarca todas essas capacidades, é dinâmica e está em constante desenvolvimento, pois é atualizada a cada momento em que ele participa de uma atividade situada de linguagem, de forma ativa e responsiva. (p. 48)

Concomitantemente ao desenvolvimento da competência discursiva, múltiplas competências podem ser trabalhadas desde a escola, visando à formação integral de nossos jovens para viver em sociedade. $\mathrm{O}$ grupo ${ }^{3}$ que atuou na construção do projeto de leitura Hip-Hop, priorizando o desenvolvimento de habilidades artísticas do Rap (música), Break (dança) e Grafite (pintura), procurou criar cenários de ensinagem em que outras habilidades pudessem ser ativadas. Partiuse do pressuposto dialógico freiriano que considera a leitura de mundo precedente à leitura da palavra, e por isso, desde a proposta temática, levaram-se em consideração os saberes prévios dos sujeitos envolvidos no processo, discutindo atividades que fossem ao encontro dos saberes culturais e identitários dos estudantes daquela escola, mas que promovessem uma ampliação, transformando esses saberes. O projeto

\footnotetext{
${ }^{3} \mathrm{O}$ grupo, que teve a assessoria do UCS-Produtore (pesquisadores da UCS e bolsistas de IC), foi coordenado pela profa. de Língua Portuguesa Carmeline Zorzi Munaro e envolveu professores de quatro turmas: uma $5^{\text {a }}$, duas $6^{\mathrm{a}} \mathrm{e}$ uma $7^{\mathrm{a}}$ série, além da coordenadora pedagógica, da diretora e da vice-diretora do turno da tarde.
} 
Hip-Hop levou em consideração a mensagem emblemática do pensamento freiriano, que preconiza construir escolas que todos: crianças, jovens, professores, pais e funcionários, gostassem de freqüentar como protagonistas ao invés de meros espectadores. Assim, provavelmente diminuiríam as taxas de abandono escolar voluntário e se eliminaria o trágico fenômeno da exclusão compulsória.

\section{Considerações acerca da dinâmica do trabalho}

Durante o processo de execução do projeto, as atividades foram organizadas para que, além da competência discursiva de leitura, múltiplas capacitâncias fossem desenvolvidas, buscando a mobilização de saberes de forma interdisciplinar. Para isso, trabalharam articuladamente no projeto professores de Matemática, Ciências, Educação Artística, Educação Física, História, Geografia e Língua Portuguesa, além de agentes convidados: grafiteiro, músico, arquiteto entre outros.

As quatro turmas de estudantes foram divididas em três grupos, os quais foram constituídos por integrantes de turmas e séries diferentes, visando a respeitar a heterogeneidade constitutiva, concomitantemente à homogeneidade interativa, fatores propulsores da coesão dos grupos e potencialmente qualificadores das intenções e ações dos estudantes.

A primeira atividade foi a apresentação do projeto aos estudantes. Houve uma palestra com a orientadora educacional da escola, abordando a história do Hip-Hop, ilustrada por slides e música. Nessa ocasião, procedeu-se à composição dos grupos e procurou-se dirigir o foco para a responsabilidade compartilhada de execução do trabalho com o objetivo de expandir e intensificar atitudes de cooperação.

A segunda atividade foi a construção de maquetes. Os estudantes assistiram à palestra de uma arquiteta e, paralelamente, à explicitação da função desse recurso arquitetônico. A professora de Matemática procedeu a um trabalho de desenvolvimento das habilidades de compreensão da noção de escala e de medidas matemáticas, com exercícios de produção de plantas baixas da sala de aula, da escola, inclusive das casas de alguns estudantes. A professora de Artes orientou uma pesquisa sobre os materiais que seriam usados 
na confecção das maquetes e coordenou as respectivas construções, ficando cada uma delas sob a responsabilidade de grupos distintos. Propôs-se também, como atividade didático-pedagógica, a comparação entre maquetes das cidades de São Paulo e de Nova Iorque, evidenciando semelhanças e ressaltando diferenças arquitetônicas, entre esses dois mega centros urbanos, bem como destacando a importância da preservação de seus pontos turísticos e culturais. Temas associados à confecção da maquete também foram estudados nas disciplinas de História e de Geografia, espaço em que houve um trabalho de leitura dos mapas das duas cidades. A produção da maquete serviu de referência para o trabalho de comparação estético-arquitetônica entre os bairros de Alphaville (alto padrão socioeconômico) e uma Favela, na cidade de São Paulo (baixo padrão socioeconômico).

É possível dizer que, sob o ponto de vista motivacional essa atividade foi exitosa, no sentido de ter envolvido plenamente os estudantes, que demonstraram prazer em executá-la. Entretanto, sob o ponto de vista processual (processamento cognitivo), o trabalho pedagógico poderia ter enfatizado com mais propriedade a atenção focal dos estudantes, contribuindo substancialmente para o desenvolvimento da estruturação perceptiva dos sujeitos envolvidos, com o intuito de obter crescente qualidade na realização de análises contrastivas. Além disso, há de se considerar os possíveis ganhos substanciais, no tocante à utilização do raciocínio espacial, durante a execução de plantas baixas, maquetes e leitura de mapas. Essas atividades potencializaram a compreensão da organização geopolítica de uma metrópole, incrementando a noção de mundo dos estudantes acerca das diferenças econômicas e culturais marcantes na sociedade. Além da oportunidade de experienciar o trabalho de composição arquitetônica da maquete e da exploração de materiais novos, os estudantes tiveram acesso à linguagem matemática de cálculos, de geometria e de escala, participando de um processo de construção de aprendizagens significativas com oportunidades pedagógicas de desenvolver níveis crescentes de pensamento abstrato.

A terceira atividade envolveu grafitismo. Inicialmente estava planejada uma fala de um professor expert no citado tema, questionando o grafite enquanto escrita ou desenho, ato de vandalismo ou manifestação artística, pichação ou arte urbana, fazendo alusão geo- 
histórica ao início do movimento, até os dias de hoje, no Brasil e no mundo, principalmente nas grandes cidades. Entretanto, o professor em vez de fazer a fala planejada, preferiu "ir direto à prática", com a intenção de discutir as questões elencadas acima, à medida que os estudantes iam elaborando seus trabalhos, usando como temas a saúde, o meio ambiente e a paz.

Embora os temas elencados sejam relevantes para qualquer comunidade escolar, e a intenção do mediador de partir da prática do grafite para uma maior reflexão teórica acerca dessa prática possa sinalizar uma experiência metodológica promissora, algumas evidências demonstraram que os frutos da atividade ficaram aquém do projetado. Como o mediador abriu mão da sua fala, não foi desponibilizado nenhum suporte teórico que estimulasse nos estudantes uma compreensão substancial do mundo do grafitismo, isso associado ao fato de que esse conteúdo não foi abordado de forma articulada pelas professoras participantes do projeto, a construção dos painéis foi predominantemente alicerçada no conhecimento prévio de cada sujeito envolvido, seja nos aspectos conceitual, procedimental ou atitudinal. Com relação aos temas tratados: saúde, meio ambiente e paz, é preciso dizer que serviram mais de inspiração artística para a execução de "painéis" do que de ponto de partida para reflexões acerca de questões mais complexas, envolvendo princípios de convivência social, tolerância, alteridade, solidariedade, proteção à saúde individual, coletiva e ambiental, entre outros.

Por falta de material, os estudantes no lugar de grafites produziram desenhos que foram considerados painéis. Procedeu-se a um trabalho de pintura/desenho e (re) pintura/desenho, buscando aprimorar o produto para ser exposto na Multifeira, atitude recorrente que possivelmente tenha origem na concepção pedagógica laudatória de legitimar mais o produto do que o processo, demonstrando que a condução do trabalho não deu conta de um aspecto fulcral da pedagogia de projetos que é o contínuo desenvolvimento de habilidades e competências. A atividade pedagógica ficou prejudicada pelo fato de que, no lugar de spray, usou-se lápis preto, lápis de cor e giz de cera e o suporte textual foi a folha A3, ao invés da parede. Entretanto isso poderia ser considerado como um ajuste plausível, desde que o mediador não perdesse de vista o foco processual da atividade pedagógica, ou seja, desvelar para os sujeitos envolvidos o universo 
discursivo do grafite, levando em consideração o contexto de produção desse gênero de texto.

Embora os estudantes possam ter tido acesso ao discurso do grafite, por intermédio da assessoria direta do professor, não vivenciaram a atividade de linguagem de produção de um verdadeiro grafite, o que de certa forma comprometeu o processo de desenvolvimento de múltiplas competências associadas a essa prática social, inclusive da competência discursiva de apropriar-se desse gênero de texto para participar com alguma autonomia da prática social da grafitagem, visto que, para Perrenoud, "toda competência está fundamentalmente ligada a uma prática social de certa complexidade" (1999, p. 35).

Outras habilidades poderiam ter sido mobilizadas nessa situação, em direção à busca do material e do espaço físico adequado para a execução plena da atividade planejada. Algumas experiências já demonstraram o êxito de ações conjuntas entre estudantes, professores, pais e gestores, na construção de soluções para enfrentar o problema dos custos de um projeto de trabalho. ${ }^{4}$ Isso implica o desenvolvimento de habilidades empreendedoras, resolutivas, criativas, colaborativas entre outras. Se os gestores, os professores ou os próprios estudantes da turma se mobilizassem, buscando os recursos para o pleno desenvolvimento da atividade em curso, provavelmente o nível de compreensão e conscientização sobre essa atividade de grafitagem fosse de outra magnitude.

A quarta atividade dizia respeito à leitura como uma prática possivel, desde a escola. Depois da palestra do coordenador do projeto de pesquisa UCS-Produtore, que tematizou as diferentes formas de leitura, tendo em vista diferentes práticas letradas da sociedade (atividades/ação de linguagem significativas), por intermédio de diferentes gêneros textuais, procedeu-se à leitura da canção do gênero Rap "Alphaville e a favela" de Spainy e Trutty. A professora de Língua Portuguesa, responsável por essa atividade, enfatizou as diferenças das duas realidades socioculturais retratadas na letra, além de sugerir produção adaptando o gênero canção para narração de histórias e paródias.

A professora justificou sua opção por essas atividades rotineiras de adaptação e produção de paródias a partir de um texto,

\footnotetext{
${ }^{4}$ Ver Baltar (2006), parte II.
} 
pelo fato de apresentar lacunas em sua formação inicial quanto ao trabalho com a multimodalidade do gênero canção. De fato, é mais comum trabalhar apenas a letra da música, desconsiderando que para a leitura integral de um texto desse gênero na busca da construção de seu sentido, sob o ponto de vista textual-discursivo, é imprescindível levar em consideração harmonia, ritmo, melodia, como componentes da música. Em outras palavras, tanto a letra, quanto a música, componentes do gênero canção, são constitutivos da tríade aludida por Bakhtin (1997): unidade composicional, unidade temática e estilo, para caracterizar esse gênero de texto/discurso. Além disso, o caráter multimodal é determinante para circulação desse gênero na sociedade: na mídia, nos suportes, nos ambientes discursivos.

Nesse caso, a professora poderia partir da ficha técnica da canção, em que consta compositor da letra e da música e os instrumentistas que a executam. Poderia chamar atenção para a linguagem musical quando da audição do RAP. Esse trabalho poderia contar com o apoio dialógico de um especialista, que, em princípio, poderia ser um músico convidado/palestrante, ou ainda, um estudante participante do projeto que tivesse essa habilidade/competência desenvolvida. Em síntese, a leitura de um gênero textual de forma responsiva, aos moldes de Bakhtin (1997), levando em consideração as suas condições de produção e o conhecimento de como ele funciona dentro da sociedade, nos seus mais diversos ambientes discursivos é uma potente ferramenta para o desenvolvimento da competência discursiva dos sujeitos envolvidos nas práticas letradas dessa sociedade.

Nesse sentido é possível dizer que a competência discursiva de um sujeito se amplia cada vez que ele se apropria de um gênero textual e atua responsivamente mediado por esse texto/gênero, levando em consideração o seu contexto de produção; ou seja, a atividade de linguagem significativa e o respectivo ambiente discursivo em que, em tese, ${ }^{5}$ o gênero circula. Dito de outra maneira, a apropriação consciente de um gênero por um ator de linguagem funciona como um recurso importante para o desenvolvimento de sua competência discursiva,

\footnotetext{
${ }^{5}$ Embora seja possível catalogar os gêneros textuais/discursivos associando-os aos ambientes discursivos em que prioritariamente circulam, muitos gêneros, como meios de agir sociodiscursivamente, podem transpor os limites de seus ambientes discursivos natos, ocorrendo em qualquer lugar social, no momemto em que acontece uma atividade/ação de linguagem.
} 
visto que lhe permite transitar em determinados lugares sociais e interagir com outros atores.

Assim, os estudantes que participaram da atividade de leitura da canção/Rap, da mesma forma que no caso anterior da atividade do grafitismo, não tiveram acesso a toda potencialidade de desenvolvimento de habilidades/competências que poderiam entrar em jogo nessas duas atividades de linguagem. É possível que um fator restritivo seja a dificuldade que os professores encontram em forjar atividades de linguagem significativas na escola, que dialoguem com atividades significativas de outros lugares sociais, extrapolando as rotinas de sua unidade escolar.

É possível asseverar também que essa lacuna pode advir da formação inicial dos professores, já que são poucos os cursos de graduação que oferecem em seu currículo o tratamento adequado à pedagogia de projetos.

A quinta atividade foi voltada à produção de uma música Rap. Iniciou com a fala do professor sobre a história do Rap. Posteriormente, os estudantes elaboraram Raps (letra e música) com sua assessoria. Segundo análise da professora coordenadora do projeto essa atividade teve êxito pela tenacidade do professor de música de compor algumas canções, juntamente com o grupo de estudantes envolvidos no projeto. O professor coordenou a atividade de composição e adaptação de melodias às letras que os estudantes compunham, trabalhando a prosódia do Rap.

No momento em que se trabalha a prosódia, isto é, a distribuição da letra da canção em frases melódicas, de acordo com a acentuação/divisão rítmica, é possível ressaltar a característica multimodal do gênero canção, evidenciando a diversidade das habilidades que estão em jogo. Esse enfoque pode ser adotado tanto na atividade de leitura quanto na atividade de produção do gênero. Para isso acontecer é necessário que o professor busque a compreensão de como o gênero está estruturado e, sobretudo, como funciona na sociedade. Uma vez apropriando-se dele pode criar as condições para que os estudantes também dele se apropriem.

A sexta atividade foi centralizada na danca, Break. O professor que falaria sobre dança de rua - Break foi substituído pela professora de Ed. Física, que teve alguma dificuldade em conduzir a atividade de construção de coreografias, segundo relato da coordenação do projeto. 
De certa forma isso ocorreu pelo fato de a professora não ser especialista e de não ter conseguido mobilizar, no grupo, estudantes que demonstravam ter essa habilidade mais desenvolvida, uma vez que essa modalidade de dança é prática recorrente entre a comunidade em questão. Aqui se pode chamar atenção para as dificuldades que alguns professores enfrentam quando necessitam articular/administrar os papéis dentro da execução de um projeto, compartilhando poderes e responsabilidades com estudantes, especialistas, enfim, indo ao encontro das melhores soluções para a execução das atividades planejadas.

Considerando que um dos objetivos da escolha do trabalho com Hip Hop era justamente resgatar e ampliar o conhecimento de mundo dos estudantes daquela comunidade envolvida no projeto, nesse episódio ficou configurada a dificuldade que alguns professores têm em mobilizar variáveis socioculturais a favor da consolidação e qualificação dos processos de ensinagem.

A sétima atividade dizia respeito à escolha, julgamento, da melhor composição: música (Rap), dança de rua (Break) e painel (Grafite), para apresentação na Multifeira da escola. Em princípio, estava planejado que cada um dos três grupos se dividiria em subgrupos e esses subgrupos de estudantes comporiam músicas, coreografias de dança e painéis de grafite, para que, a posteriori, fosse escolhido um trabalho que representaria o grupo maior, no dia de culminância do projeto na Multifeira da escola. Entretanto, isso não aconteceu.

O trabalho de construção de autoria que foi estimulado pelos professores coordenadores das três atividades: dança, música e grafite, não propiciou o resultado esperado. A leitura da professora coordenadora do projeto para essa questão foi que os estudantes sentiram-se constrangidos em apresentar-se para o grande público. Alguns que compuseram trabalhos nos pequenos grupos não apareceram nos dias de ensaio e da apresentação final. Uma hipótese que se cogitou foi quanto a problemas metodológico-organizacionais em relação aos ensaios que antecederam a apresentação para a Multifeira.

Os ensaios haviam sido pensados justamente para trabalhar habilidades técnicas específicas de cada atividade, além de ensejar a mobilização de componentes da estrutura psicológica dos estudantes, como auto-imagem, auto-conceito, auto-estima. Todavia alguns integrantes dos grupos se dispersaram, provocando uma quebra de 
engajamento e responsabilidade. Alguns, alegando se sentirem pouco à vontade diante do desafio, para se preservar, resolveram "abandonar o barco", deixando sozinhos os colegas, que ficaram até o final do projeto. As causas desse abandono estão sendo analisadas pelos professores da escola, que buscam entender o que houve para que nos próximos projetos isso possa ser (re)trabalhado.

Entretanto, discutiu-se com a coordenadora pedagógica da escola e com a professora coordenadora do projeto a importância de não dar um enfoque coercitivo para a apuração das causas que levaram alguns estudantes a "quebrar" o contrato. Discutiu-se que o trabalho de mediação feito pelos professores responsáveis pelas atividades junto aos estudantes, bem como o grau de articulação entre o grupo no decorrer do projeto também deveria ser estudado. Nota-se mais uma vez a precariedade do percurso formativo dos professores que estão atuando na educação básica no que tange à dimensão processual das atividades de ensinagem.

Estava prevista como parte dessa atividade a organização de júri para avaliar as obras produzidas pelos estudantes, com a discussão, mediada por especialistas, acerca dos parâmetros/critérios que seriam levados em conta no julgamento, o que proporcionaria a ampliação de saberes acerca das modalidades artísticas em pauta. Levantou-se a questão de possíveis decalagens entre o trabalho docente prescrito e realizado, espaço esse a ser ocupado pelo real trabalho do professor. $^{6}$

A atividade de culminância do projeto foi a apresentação dos trabalhos na Multifeira, para todos os estudantes e professores do turno da tarde, além de alguns pais.

Os estudantes apresentaram Raps e coreografias Break, no palco do salão da comunidade e os painéis/desenhos, que tomaram o lugar dos grafites, foram expostos nas salas de aula, juntamente com as maquetes.

\footnotetext{
${ }^{6}$ Sobre essa questão recomenda-se a leitura da tese de doutoramento "Entre o trabalho prescito e realizado: um espaço para a emergência do trabalho real do professor”. 2006. (Doutorado em Lingǘstica Aplicada e Estudos de Linguagem) - Pontifícia Universidae Católica de São Paulo, de Eliane Gouvea Lousada, orientação de Anna Rachel Machado.
} 
Após a conclusão do projeto, os estudantes responderam uma ficha de avaliação e os professores destacaram em reunião os pontos que deveriam ser revistos para a elaboração de novos projetos no futuro próximo. Tanto a análise dos estudantes quanto a dos professores foi positiva, visto que "se tratava do primeiro projeto envolvendo todos os professores e todos estudantes do turno da tarde".

Os estudantes sugeriram rever o tempo das atividades, que em alguns casos foi mal dimensionado, principalmente na construção da maquete e nos ensaios para apresentação da coreografia Break e do Rap.

Os professores elencaram algumas habilidades que foram mobilizadas nos estudantes, como o trabalho de pesquisa e de leitura, a sua participação colaborativa, seu engajamento na maioria das atividades previstas, o acréscimo de sua auto-estima etc. Destacaram o trabalho coletivo de colegas que juntos deram forma e executaram o projeto, demonstrando espírito de união e parceria. Consideraram importante o diálogo constante com o grupo de pesquisadores e sobretudo o espaço de discussão quinzenal criado na escola para fazer os ajustes necessários à execução do projeto.

A equipe de pesquisa, depois de participar da avaliação com a coordenadora do projeto e com a coordenadora pedagógica da escola, elaborou algumas considerações acerca da dinâmica dos frutos de sua participação como coadjuvante na execução do projeto HipHop: promovendo a leitura através da arte e da cultura.

Foi visível o avanço das professoras que coordenaram o projeto quanto a sua concepção acerca da validade da pedagogia de projetos de trabalho na escola. Desde o trabalho inicial da apropriação do gênero projeto até a culminância das atividades previstas, com a apresentação dos produtos elaborados pelos estudantes, houve um sensível progresso, entretanto, alguns pontos ainda podem ser desenvolvidos. A organização do tempo e espaços escolares em função das necessidades para a execução das atividades previstas no projeto é algo que deverá avançar. A harmonização entre o tratamento dos conteúdos das disciplinas: conceituais, procedimentais e atitudinais ${ }^{7}$ focados nas atividades do projeto, também é um ponto a ser (re) visto nos âmbitos intra e interdisciplinar.

\footnotetext{
${ }^{7}$ Conforme os PCNs, 1997.
} 
Alguns professores se organizaram e, na semana que antecedia uma atividade em que algum conteúdo de sua disciplina seria abordado, como recurso para desenvolver habilidades/competências, prepararam suas aulas de forma a complementar a atividade foco do projeto, o que se revelou produtivo para a compreensão geral da atividade, dando outro sentido ao trabalho de ensinagem. Foi o caso da professora de matemática e de geografia, por exemplo, em relação à atividade de construção da maquete. Outros professores, todavia, não aderiram plenamente à proposta, sugerindo que a sua representação de trabalho por projetos está desvinculada da abordagem cotidiana dos conteúdos de sua disciplina.

Por outro lado, embora haja uma idéia inicial de quais saberes serão mobilizados na execução das atividades planejadas, em prol do possível desenvolvimento de algumas competências (individuais e coletivas), estejam esses saberes ligados explicitamente aos conteúdos curriculares ou não é importante compreender que, no decorrer de um projeto, outros saberes podem entrar em jogo, acrescentando ganhos de qualidade no seu processo de execução, configurando a grande riqueza em potencial desse dispositivo pedagógico.

Em relação ao engajamento dos estudantes na execução das atividades previstas no projeto, é possível dizer que funcionou bem em algumas atividades, mas deixou a desejar em outras. Embora tenha havido falhas nas últimas atividades, por questões que podem ser creditadas tanto aos estudantes quanto aos professores, "a grande maioria demonstrou interesse" em reviver a experiência, participando de outro projeto na escola.

A repercussão positiva do projeto diante das outras escolas públicas municipais da SMECD de Flores suscitou a demanda de assessoria do grupo de pesquisa para outras duas escolas além da Leonel Brizola, que também pretendem trabalhar por projetos.

\section{Alguns resultados}

$\mathrm{Na}$ pesquisa-ação os resultados funcionam como indicadores que sustentam a tomada de decisão ao longo do processo de açãoreflexão-ação, a partir de problematizações discutidas em conjunto com os sujeitos envolvidos na experiência, em busca das transformações conjunturais desejadas. Nessa experiência de co-construção do projeto 
de trabalho "Hip-Hop: promovendo a leitura através da arte e da cultura", na Escola Municipal Leonel Brizola, de Flores da Cunha, a equipe UCS-Produtore se propôs investigar o grau de apropriação que os professores tinham acerca desse dispositivo didático-pedagógico. A análise dessa caminhada possibilitou desvelar dois aspectos principais da experiência, que estão elencados a seguir:

a) Houve ganhos por parte dos professores envolvidos no projeto no que concerne à sensibilização para o trabalho com a pedagogia de projetos na escola. As atividades de textualização e retextualização do gênero projeto feitas pela professora de Língua Portuguesa e pela coordenadora pedagógica da escola, subsidiadas pela equipe de pesquisa, foram decisivas para o aprimoraramento do grau de compreensão do que é planejar e escrever um projeto antes de colocá-lo em prática. Antes da elaboração do projeto "Hip-Hop: promovendo a leitura através da arte e da cultura", os professores consideravam projetos de trabalho as atividades rotineiras de comemoração de datas do calendário escolar, sem maior preocupação com o desenvolvimento de habilidades e competências individuais e coletivas dos sujeitos envolvidos.

b) Os professores demonstraram dificuldades em articular os conteúdos: conceituais, procedimentais e atitudinais, previstos pelo plano de estudo da escola com as atividades programadas no projeto. Isso acarretou uma sobrecarga de trabalho, visto que, além das aulas semanais destinadas às atividades do projeto, eles ainda cumpriam a carga horária rotineira de suas disciplinas.

\section{Considerações finais}

Os resultados da pesquisa-ação, aqui discutidos, endereçados para a formação continuada de professores sugerem alguns caminhos possíveis para que o processo de aquisição de competências e o vicejamento da pedagogia de projetos deixem de ser quimera e passem a ser considerados, paulatinamente, como dinâmica natural dos tempos e espaços escolares.

É preciso frisar que o projeto "Hip-Hop" que acabamos de analisar foi uma iniciativa que partiu da revelação de um estado de desconforto profissional especificamente na dimensão didáticopedagógico de uma professora de Língua Portuguesa de uma escola 
de periferia do município de Flores da Cunha-RS, cujos estudantes demonstram um quadro marcante de vulnerabilidade social. A professora socializou com o grupo de oficineiros o problema relativo ao baixo nível de motivação dos estudantes, dificultando o processo de ensinagem da Língua Portuguesa, quadro esse acentuado pela desarticulação pedagógica do corpo docente tradicionalmente decorrente do isolamento do professor em áreas específicas do conhecimento. É possível dizer que essa vulnerabilidade tenha como uma das causas a insistente organização de currículos por disciplinas, ao invés da deliberada construção de mapas curriculares, experimentalmente produtivos quando as metas educativas estão realmente voltadas para o desenvolvimento de habilidades e competências múltiplas.

Inicialmente a professora optou por buscar respostas imediatas para atenuar a zona de desconforto pedagógico em que se encontrava, caracterizada pelo baixo nível de interação sociodiscursiva com os estudantes. Considerando que esse desconforto e baixo nível de interação sociodiscurva não fosse apenas um caso isolado de uma professora com uma turma, mas sintomático daquela realidade escolar, o projeto funcionou como um dispositivo auxiliar na superação desse gap.

Embora a compreensão da potencialidade do trabalho com a pedagogia de projetos ainda esteja incipiente nos professores dessa escola, visto que ainda os conteúdos desenvolvidos no projeto e na sala de aula operam desarticuladamente, essa experiência suscitou nos professores a percepção de recursos didático-pedagógicos de efeito mediato no delineamento de estratégias de ensinagem mais potentes para efetivar o trabalho educativo com essa comunidade. Sublinha-se o fato do projeto ter possibilitado a legitimação dos referenciais identitário-culturais da comunidade e de certo modo ter minimizado a distância entre o ambiente discursivo escolar e o mundo da vida.

Em relação à interação entre os especialistas e os professores em formação, tendo como estratégia a pesquisa-ação, diríamos que, juntamente com a oferta de oficinas de sensibilização sobre ensinagem dentro do escopo da pedagogia de projetos/gêneros textuais e da abordagem por competências, tem se mostrado promissor o acompanhamento sistemático do professor envolvido na formação no seu lugar de trabalho. Esse acompanhamento permite de fato a 
implementação de ações-reflexões-ações resolutivas, que ampliam a visão dos professores acerca das propostas estudadas, dando sentido ao que foi discutido nas oficinas. Nesse caso específico, consideramos a apropriação do gênero textual projeto: de sua unidade composicional e de sua função dialógica dentro da escola como ponto decisivo para que a professora e a coordenadora se sentissem seguras na mediação das atividades de linguagem decorrentes do processo de implementação do projeto.

Em síntese, é possível dizer que, ao longo do processo de criação, execução e avaliação do projeto, dentro do escopo da pesquisaação, e sob a ótica do trabalho de ensinagem via projetos e desenvolvimento de competências, houve alguns avanços que devem se consolidar à medida que outros projetos sejam implementados na escola. Analisando essa vivência, sob as lentes da dialogicidade e do interacionismo sociodiscursivo, talvez o aspecto mais importante que se possa destacar é a sua contribuição em direção à construção de uma escola mais próxima da vida social de sua comunidade, uma escola na qual todos se sintam bem e, se apropriando dela como atores sociais, dela não se deixem expulsar, inclusive os professores.

\section{Referências}

ANDALOUSSI, Khalid. Pesquisa-ações: Ciências. Desenvolvimento. Democracia. São Paulo: EDUFSCar, 2004.

BALTAR, Marcos. Competência discursiva e gêneros textuais: uma experiência com o jornal de sala de aula. 2. ed. Caxias do Sul: EDUCS, 2006.

BRASIL. Secretaria de Educação Fundamental. Parâmetros curriculares nacionais: Língua Portuguesa. SEF: Brasília, 1997.

BROCKART, Jean-Paul. Atividade de linguagem, textos e discursos: por um interacionismo sociodiscursivo. São Paulo: EDUC, 1999.

HERNÁNDEZ, Fernando. Transgressão e mudança na educação: os projetos de trabalho. Porto Alegre: Artmed, 1998. 
.; VENTURA, Montserrat. A organização do currículo por projetos de trabalho: o conhecimento é um caleidoscópio. 5.ed. Porto Alegre: Artmed, 1998b.

PERRENOUD, Philippe. Construir as competências desde a escola. Porto Alegre: Artes Médicas, 1999.

.; THURLER, Mônica G. As competências para ensinar no século XXI: a formação dos professores e o desafio da avaliação. Porto Alegre: Artmed, 2002. 